\title{
Causation, Projection, Inference, and Agency
}

DOI:

10.1093/acprof:oso/9780198723172.003.0002

\section{Document Version}

Accepted author manuscript

Link to publication record in Manchester Research Explorer

\section{Citation for published version (APA):}

Beebee, H. (2015). Causation, Projection, Inference, and Agency. In R. Johnson, \& M. Smith (Eds.), Passions and Projections: Themes from the Philosophy of Simon Blackburn (pp. 25-48). Oxford University Press.

https://doi.org/10.1093/acprof:oso/9780198723172.003.0002

\section{Published in:}

Passions and Projections

\section{Citing this paper}

Please note that where the full-text provided on Manchester Research Explorer is the Author Accepted Manuscript or Proof version this may differ from the final Published version. If citing, it is advised that you check and use the publisher's definitive version.

\section{General rights}

Copyright and moral rights for the publications made accessible in the Research Explorer are retained by the authors and/or other copyright owners and it is a condition of accessing publications that users recognise and abide by the legal requirements associated with these rights.

\section{Takedown policy}

If you believe that this document breaches copyright please refer to the University of Manchester's Takedown Procedures [http://man.ac.uk/04Y6Bo] or contact uml.scholarlycommunications@manchester.ac.uk providing relevant details, so we can investigate your claim.

\section{OPEN ACCESS}




\title{
Causation, projection, inference and agency
}

\author{
Helen Beebee
}

Please do not cite this version. The published version is:

'Causation, Projection, Inference and Agency', in Passions and Projections: Themes

from the Philosophy of Simon Blackburn, ed. M. Smith \& R. Johnson (New York:

OUP, 2015)

The world, or rather that part of it with which we are acquainted, exhibits as we must all agree a good deal of regularity of succession. I contend that over and above that it exhibits no feature called causal necessity, but that we make sentences called causal laws from which (i.e. having made which) we proceed to actions and propositions connected with them in a certain way, and say that a fact asserted in a proposition which is an instance of causal law is a case of causal necessity.

F. P. Ramsey, 'General Propositions and Causality' $(1929,160)$

\section{Introduction}

Simon Blackburn endorses a 'projectivist' interpretation of Hume on causation. ${ }^{1} \mathrm{He}$ also takes Hume thus interpreted to be more or less right about causation; at any rate, he suggests as much in various places, and such a view is in any case entailed by the projectivism about modality more generally for which he explicitly argues (1987). On this view - which I shall call the 'Hume-Blackburn' view ${ }^{2}$ - causal claims project our inferential commitments onto the world, rather than representing a mind-independent relation that somehow licences those inferences.

In this chapter, I explore the prospects for a projectivist account of causation of the kind that Hume (thus interpreted) and, apparently, Blackburn endorse. The major problem for such an account - setting aside traditional worries about projectivism more generally - is that it is unclear whether it yields an asymmetric relation between causes and effects. The cornerstone of the Hume-Blackburn account

\footnotetext{
${ }^{1}$ See Blackburn1984, 210-12; 1990; 2008, 24-33; the interpretation is developed in more detail in Beebee 2006, Ch.6 and Coventry 2006.

${ }^{2}$ It is of course highly controversial whether or not Hume actually subscribed to this view. I tentatively believe that he did - or at least that he did when he wrote the Treatise (see my 2006, Ch. 7) - and in the rest of this chapter I shall assume that I'm right.
} 
is the thought that what is projected is a habit of inference. But inference runs in both directions: we infer causes from effects just as happily as we infer effects from causes. Hume himself solves this problem by stipulation: causes precede their effects. But in the absence of a satisfactory account of why causes precede their effects - and evidential relations on their own would appear to provide no such account - Hume's stipulation appears at best ad hoc; and at worst it stands a fighting chance of simply being empirically false. A second strand of projectivist thinking about causation with its roots in the work of Frank Ramsey, and given a much fuller articulation by Huw Price - aims to deliver asymmetry by conceiving causation as a projection not of our habits of inference but of our perspective as deliberating agents. ${ }^{3}$

Conceiving the question of a viable projectivist account of causation as a straight choice between inference and agency, however, masks two broader commonalities. First, the Ramsey-Price view, like the Hume-Blackburn view, takes causation to be an evidential relation. What distinguishes the former from the latter is not the eschewal of evidential relations as the way to understand causation, but the claim that it is evidential relations of a certain sort-viz, those that stem from the perspective of the agent - that characterise causation.

Second, there is a deep connection between both views on the one hand and a long-running theme in the literature on conditionals on the other. Causation is, of course, a conditional relationship in a sense: effects generally depend on their causes, and there is a long-standing tradition within Humeanism of understanding causal laws (' $A$ s cause $B \mathrm{~s}$ ') as equivalent to, or at least very closely related to, generalised conditionals ('if something is an $A$, it will be followed by a $B$ '). Projectivist accounts of causation take the 'truth' of causal claims to be an expression or projection of our

\footnotetext{
${ }^{3}$ Price's global expressivism perhaps makes 'projectivist' an unhappy term to use to describe his account of causation, since (unlike Blackburn) Price does not believe in the kind of representational language with which projectivist talk might be contrasted. On the other hand, Price describes his view of causation as 'perspectival', and that, presumably, is supposed to draw a contrast with something that is non-perspectival (the laws of physics, say), even if the non-perspectival also fails to be representational. (It may be that non-perspectival claims, but not the perspectival ones, are - in Price's sense of the term - 'e-representations' (see Price, this volume, §5).) At any rate, supposing that local projectivism is a viable option in principle, the local projectivist about causation can in principle appropriate Price's view on causation to suit her own ends; there is nothing in Price's account of causation that depends on global expressivism. In a sense, then, the Price of this chapter is this fictional character and not the real Price; but given my purposes this should not matter very much.
} 
attitudes: the conditional structure of reality is in some sense no more than the conditional structure of our thought ('if I see an $A$, I shall regard it as grounds for expecting a $B$ ', or perhaps 'if I do $a, b$ will follow'). But there is also a long tradition, tracing back to Ramsey himself, of holding that indicative (and counterfactual) conditionals themselves lack truth conditions: to be confident that if $X$, then $Y$ is to be confident that $Y$ on the supposition that $X$. One's degree of confidence in the latter can be represented as $\operatorname{Pr}(Y / X)$, but this degree of confidence does not amount to a degree of confidence that some proposition is true.

We might, then, attempt to extract a projectivist account of causation from a 'projectivist' account of conditionals: we conceive of causes as grounds for inferring effects because the conditionals we sign up to in conceiving causes in this way are themselves expressions of our inferential commitments (they are, to use Ryle's expression, 'inference tickets') rather than statements of objective conditional facts. (This is not a new proposal; indeed, I take it to be pretty much Ramsey's view.)

One virtue of proceeding in this manner is that it delivers independent motivation for what I suspect many philosophers regard as a deeply unattractive aspect of projectivism about causation: the fact that it renders our causal talk nontruth-apt or non-fact-stating (at least on a realist, as opposed to a quasi-realist, understanding of the notions of 'truth' and 'fact'). Projectivists themselves, of course, consider this cost, if they regard it as a cost at all, to be worth the benefit, where the benefit is broadly metaphysical. We can have our cake, constructed only from the delectably sparse ingredients of the Humean mosaic, and eat it too - that is, we can agree with the realists that causal talk and thought are crucially important to our cognitive and practical lives and that to advocate the eschewal of causal vocabulary, or to analyse it away, would be a mistake. The benefit of regarding conditional discourse as non-fact-stating, by contrast, lies not in its metaphysics but in its logic and epistemology - relatively neutral territory, in other words, from the point of view of the hotly contested battle lines that are fought over by projectivists about causation and their 'objectivist' opponents (though it may be that objectivists about causation will want to resist the claim that conditionals are non-fact-stating too - indeed, they better had if they agree that causation should be analysed in terms of conditionals, as subscribers to the counterfactual analysis do).

Having sketched the Hume-Blackburn and Ramsey-Price versions of projectivism about causation and explained the latter's solution to the worry about 
causal asymmetry in $\S 2$, in $\S 3$ I discuss accounts of conditionals that regard them as 'rules' or 'inference tickets' rather than propositions, and explain the connection between degrees of confidence in conditionals on the one hand and conditional probabilities on the other. I then flesh out the suggestion made above, that a projectivist account of causation can in principle be premised on the kind of account of conditionals just described, and explain how, in that light, the fundamental difference between the Hume-Blackburn and Ramsey-Price positions can be seen as a difference in attitude to conditional probabilities. Since the Ramsey-Price version of this view can, and the Hume-Blackburn version cannot, account for the asymmetry of causation, the Ramsey-Price version is preferable. In $\S 4$, I say something about what divides the kind of conditional projectivist account of causation discussed earlier and the kind of conditional objectivist account held by defenders of the counterfactual analysis of causation - both of which agree on (or at least can be used to serve the cause of) a broadly Humean view of what there is. In $\S 5$, I briefly sum up.

\section{Two versions of projectivism, and their ancestry}

Hume locates the impression-source of the idea of necessary connection in the inference we draw from causes to effects - an inference that is itself a matter of 'Custom or Habit' $(1748 / 51,43)$ : having observed $C$ s being followed by $E$ s on sufficiently many past occasions, on observing a new $C$ I come to expect an $E$ to follow. The central question for interpreters of Hume has been what the implications of this discovery are supposed to be for our idea of causation. Hume appears to hold that, given its impression-source, the idea of necessary connection cannot represent any real, mind-independent relation between causes and effects. But he shows no inclination to retract his earlier claim that the idea of necessary connection is a component of the idea of causation. Nor does he hold that causal claims are claims about our own inferences: in saying that $c$ caused $e$, I am not merely reporting that on observing $c$ I came to expect $e$. Nor does he reject our causal talk as unintelligible or false: he provides us with 'rules by which to judge of causes and effects' (1739-40, 173) and makes ample use of causal claims himself.

How, then, can Hume simultaneously hold, as he appears to, that the idea of necessary connection represents neither a feature of us - the 'determination of the mind to pass from one object to its usual attendant' $(1739-40,165)$ - nor a feature of the external world; that that idea is an essential component of our idea of causation; 
and that we can (and generally do) legitimately deploy that idea when thinking and talking about the world around us? Standard interpretative options involve giving up on one or other of these claims. For example, John Wright (1983) takes the idea of necessary connection to represent (albeit inadequately) the cause as having some feature such that, were we to observe it (which, unfortunately, we cannot), we would be able to infer the occurrence of the effect a priori. The standard 'naïve regularity theory' interpretation, according to which Hume takes causation to be merely a matter of constant conjunction, contiguity and temporal priority, instead gives up on the thought that the idea of necessary connection is an essential component of our idea of causation.

The core of the projectivist interpretation is, as Blackburn puts it, is the thought 'that dignifying a relationship between events as causal is spreading or projecting a reaction which we have to something else we are aware of about the events - Hume thought of this input in terms of the regular succession of similar such events, one upon the other. Exposed to such regularity, our minds (cannot help but) form habits of expectation, which they then project by describing the one event as causing the other' $(1984,210-11)$. The primary virtue of such an interpretation, I think, is that it allows Hume to endorse all three of the claims listed above, just as he appears to do. On a projectivist interpretation, our causal talk is the expression of the inferential habit that Hume identifies as the supplier of the impression-source of the idea of necessary connection. So the idea of necessary connection does not represent anything at all - its function is to express rather than to describe - and our causal talk and thought, qua expression of our habit of inference, is entirely legitimate.

Indeed, our causal talk and thought is not merely legitimate but normatively constrained. The purpose of the inferential habit Hume identifies - let's call it 'causal reasoning' - is to deliver true beliefs about 'matters of fact' not currently present to the memory or senses, and it succeeds in doing this, to the extent that it does, by tracking nature's regularities: nature has 'implanted in us an instinct, which carries forward the thought in a correspondent course to that which she has established among external objects' $(1748 / 51,55)$. This is something we can be, and become, better or worse at: we can hone our habit, for example, by making more careful observations and by exposing ourselves to a wider range of regularities. And we need not confine ourselves to the animal 'custom or habit' kindly implanted in us by nature: we can deploy more sophisticated forms of causal reasoning, delivering more, 
and more accurate, judgements concerning causes and effects by following Hume's rules. (Thus, for example, when we notice that $E$ s are sometimes preceded by $D$ s and sometimes by $F \mathrm{~s}$, we can legitimately infer that the $D$ s and the $F$ s share some hidden feature, $C$, that is the underlying cause of $E$.)

The judgement that $c$ caused $e$ thus in effect does more than merely express a habit of inference. It expresses - in Blackburn's words - a 'habit of reliance' (1984, 211), that is, a commitment to treating certain kinds of event (the $C$ s) as grounds for inferring the occurrence of certain other kinds of events (the $E s$ ). That commitment is up for critical evaluation - inferring $E$ s from $C$ s might in fact be a really bad idea, or it might be a good idea but one for which I happen to lack decent evidence - and it is the existence of such standards of evaluation that makes what Price calls 'the objective mode of speech' $(1998,125)$ appropriate: makes it appropriate, that is, to treat causal utterances as claims to be asserted and denied, questioned, revised in the light of the evidence, and so on. Or - to go the full quasi-realist hog - the relevant standards 'earns [the quasi-realist] the right to the notion of truth, and a notion of the true causal structure of things' (Blackburn 1984, 211).

This, then, is roughly the view that Blackburn attributes to Hume and, I take it, roughly the view that Blackburn himself holds. One might, of course, take issue with a projectivist view about causation for a variety of reasons. My concern in this paper, however, is with whether the Hume-Blackburn approach in particular - according to which what is projected is our 'habit of reliance' - has sufficient resources to capture everything we need to say about causation, and in particular whether it has the resources to capture the asymmetry of causation. The basic problem is that a habit of reliance, or the conception of causes as grounds for inferring effects, generally works in both directions: effects are equally grounds for inferring causes. I engage in causeto-effect reasoning when I press the brake pedal in order to stop, or eat a sandwich in order to feel less hungry; I engage in effect-to-cause reasoning when I infer from the sound of a window being smashed downstairs that there is an intruder nearby, or I infer from the alert on my laptop screen that it's low on battery. So while inference might get us as far as a symmetric notion of causal connection, it doesn't seem that it can get us all the way to the asymmetric notion of causation. 
Hume, of course, effectively solves this problem by stipulating that causes precede their effects. (Or rather, he presents an argument against simultaneous causation (1739-40, 76). That causes cannot come after their effects is not something he seems to feel any need to justify.) Such stipulation is both undesirable in itself, since it rules out backwards causation a priori, and unsatisfying, since it fails to explain why our concept of causation is asymmetric. It is we who 'call the one object, Cause; the other, Effect' $(1748 / 51,75)$; the question is, why do we do this, rather than merely saying that the two objects are (symmetrically) causally connected to each other?

Lack of a satisfying explanation here is a less pressing concern for the objectivist; after all, if our causal talk latches on to a mind-independent feature of reality, then the asymmetry of causation itself serves to explain the asymmetry of our concept (though of course the former may itself require explanation). For the projectivist, however, no such explanation is available: we need to find some feature of $u s$ that is sufficiently important that we come to project it onto the world of Humean regularities. For the projectivist of the Hume-Blackburn variety, then, for whom the root of causation lies in our 'habits of reliance', we need an explanation for why our concept of causation is asymmetric when our habits of reliance, apparently, are not; and no such explanation appears to be at hand.

This problem - or at least a close relative of it - is recognised by Frank Ramsey (1929). Ramsey's view of unrestricted universal generalisations, or what he calls 'variable hypotheticals', shares with the Hume-Blackburn account of causation a broadly projectivist and evidentialist approach. He explains belief in variable hypotheticals ('all $A \mathrm{~s}$ are $B \mathrm{~s}$ ') in terms of a 'habit of singular belief', viz, the habit of inferring the presence of a $B$ on encountering an $A$. But this inferential habit is one that is susceptible to normative evaluation, so that variable hypotheticals are "not judgments but rules for judging "If I meet a $\phi$, I shall regard it as a $\psi$ " ' $(1929,149)$. Thus if you and I disagree about whether or not all $A \mathrm{~s}$ are $B \mathrm{~s}$, we are disagreeing, in effect, about which rule ought to be adopted. But variable hypotheticals enshrine no asymmetry, and so Ramsey's account cannot, as it stands, serve as an account of causal laws:

We have now to explain the peculiar importance and objectivity ascribed to causal laws; how, for instance, the deduction of effect from cause is conceived as so radically different 
from that of cause from effect. (No one would say that the cause existed because of the effect.) It is, it seems, a fundamental fact that the future is due to the present, or, more mildly, is affected by the present, but the past is not. What does this mean? It is not clear and, if we try to make it clear, it turns into nonsense or a definition: 'We speak of ratio essendi when the protasis is earlier than the apodasis Df.' We feel that this is wrong; we think there is some difference between before and after at which we are getting; but what can it be? $(1929,157)$

Ramsey's solution to the problem is to focus on the fixity of the past from the perspective of the deliberating agent, and in particular on the fact that 'any possible present volition of ours is (for us) irrelevant to any past event. To another (or to ourselves in the future) it can serve as a sign of the past, but to us now what we do affects only the probability of the future. This seems to me the root of the matter; that I cannot affect the past, is a way of saying something quite clearly true about my degrees of belief. Again from the situation when we are deliberating seems to me to arise the general difference of cause and effect' $(1929,158)$. Roughly speaking (I'1l fill in some more detail later on), the idea here is that while in general some present (or future) known states of affairs $A$ can serve as evidence for, and hence grounds for inference to, some past (or present) states of affairs $B$, so that $\operatorname{Pr}(B / A)>\operatorname{Pr}(B)$, in the special case where $A$ is an action I am currently considering performing this probabilistic relation never obtains for any event $B$ that is in the past.

Imagine, for example, that I placed my bet on Horse yesterday, and now (not having check the result) I think it $25 \%$ likely that Horse has won $(B) \cdot \operatorname{Pr}(B / A)$ will be $25 \%-\operatorname{Pr}(B / A)=\operatorname{Pr}(B)$ - for any action $A$ I might now deliberate about performing. I cannot, for example, make it any more or less likely that Horse won by tearing up my betting slip, booking an expensive holiday that I can only afford if Horse won, or making a wish to the effect that Horse won. Of course, were I to find out that Horse won (or lost), $\operatorname{Pr}(B)$ would change to close to 1 (or 0 ); but finding out that Horse won (or lost) is not an action I can coherently deliberate about performing. I can deliberate about whether or not to find out the result of the race, whatever that might be; but of course the likelihood that Horse won given that I do that is still $25 \%$.

For Ramsey, then, the asymmetry of causation stems from the asymmetry of the past and the future from our deliberative perspective. Does this provide the needed explanation, compatible with a broadly projectivist outlook, for the asymmetry of 
causation? Well, it's certainly a step in the right direction. If Ramsey is right about the probabilistic independence, from the deliberator's point of view, of prospective actions from prior states (call this thesis 'Probabilistic Independence of Prior States from Actions', or PIPSA for short), then his account does what I earlier said needs to be done: it provides a basis in us for making a distinction between causes and effects - one that explains why causes precede their effects, and so why causation is asymmetric, rather than taking it as a brute fact.

There are problems lurking, however. First, Ramsey appears to take PIPSA as a straightforward psychological fact. But clearly we need to regard PIPSA as a normative requirement on the distribution of degrees of belief. After all, the claim that our degrees of belief happen to satisfy PIPSA (to the extent that they do) itself demands explanation; and presumably (and indeed in fact, as we shall see) such an explanation would need to explain why it is sensible or reasonable for them to do so. Consider Hume's inferential story. Our tendency to infer Bs from $A$ s just when $A$ s and $B$ s have been constantly conjoined in our experience is not a mere psychological fact; it is one that has a clear purpose, viz, it provides us with a method for tracking nature's regularities. Similarly, we need an explanation for why it is appropriate to abide by PIPSA: what is the pay-off for assigning our degrees of belief in this way? In the absence of any such pay-off, it would seem that the asymmetry of causation has its roots in a mere psychological foible, and it would be unclear why we should regard asymmetry as the deeply important feature of causation that we do.

Second, and relatedly, there seem to be cases, not involving backwards causation, where it would be irrational to satisfy PIPSA - that is, cases where (unlike the Horse case above) prospective actions would affect the likelihood of prior states. So-called 'medical Newcomb' cases fit this model. For example, to borrow a case of Price's (1991), suppose that a pre-migrainous state $(B)$ tends to induce not only a migraine but also a strong desire for chocolate, and Coco knows this. Coco wants to eat chocolate $(A)$, but he also wants to avoid a migraine. Clearly Coco should go ahead and eat the chocolate given what he knows about the causal structure of the situation, since doing so will not increase his risk of a migraine. On the other hand, eating chocolate would be evidence that Coco is in fact in a pre-migrainous state: it seems that he should not set $\operatorname{Pr}(B)=\operatorname{Pr}(B / A)$, contrary to what PIPSA recommends. Medical Newcomb cases therefore appear to constitute counterexamples to PIPSA. 
These problems are taken up by Price (Menzies and Price 1993; Price 1986, 1991, 1992, 2007), who, like Hume and Blackburn, sees causation not as a fully objective, mind-independent feature of reality but instead as a facet of our own evidential perspective. However, Price, like Ramsey, takes our distinctive perspective as agents as the key to understanding causal asymmetry. The basic idea is that the notion of causation is to be extracted from the notion of evidential probability evidential probability itself being a perspectival matter, a matter of what can and cannot count as evidence for us. The key to causal asymmetry is the fact that, qua deliberators, we divide the world into (as Price puts it) 'fixtures' and 'options' (2007, 274-7): features of the world over which we have no control (fixtures) and those that it is up to us to bring about (options). What counts as a fixture is in turn determined by what we regard as either known or knowable: 'knowns' and 'knowables' are fixtures rather than options because 'it seems incoherent to treat something both as an input available to the deliberative process, at least in principle, and as something that can be decided by that process. Control trumps a claim to knowledge: I can't take myself to know that $P$, in circumstances in which I take myself to be able to decide whether $P$, in advance of that very decision' $(2007,275)$. Thus, for example, Coco cannot coherently regard avoiding a pre-migrainous state as an indirect option something he can bring about by avoiding the chocolate - while simultaneously regarding his being, or not being, in a pre-migrainous state as a 'fixture': something that he could come to know about independently of whether or not he opts for the chocolate. $^{4}$

Leaving Coco aside, how does the fixtures/options asymmetry transpose into a past/future asymmetry and thence into causal asymmetry? The relation between the fixtures/options distinction and the past/future distinction is not that of identity, since we have to regard at least some future facts as fixtures for the purposes of deliberating. If I am deliberating about what time to leave the house in order to catch the $8 \mathrm{pm}$ showing at the cinema, I regard the (future) start time of the film as a fixture. But of course I will only regard the start time as a fixture if I take it to be something that lies outside my control relative to the options I am currently considering. (What time I leave the house makes no difference to the start time; hence I hold the start time

\footnotetext{
${ }^{4}$ This principle is much discussed in the debate about free will and determinism; see e.g. Ginet 1962 and Sorensen 1984. There is also, I think, much to be said about the way in which this debate connects with the Ramsey-Price view.
} 
fixed.) In a different deliberative situation, the start time might not count as a fixture. If I wanted to affect the start time - say because I knew that a bomb was due to be detonated in the cinema at $8.15 \mathrm{pm}$ - then the start time would become an indirect option for me rather than a fixture. I might consider calling the police, for example an option that, from my deliberative perspective, would be pointless if I regarded the $8 \mathrm{pm}$ start time as a fixture.

What lies in the past, by contrast, is a fixture for us 'by default', as Price puts it: 'the fixed past principle, or FPP, [is] something like a piece of naïve physics' (2007, 277). But FPP is to be regarded not as a conceptual truth, akin to Hume's somewhat unsatisfying stipulation that causes precede their effects; rather it is an empirical principle - one that we can imagine suspending in strange enough circumstances (ibid.). Moreover, we can (just about) imagine a being whose epistemic orientation in time is exactly the opposite of ours, so that it can 'remember' facts about the (our) future and regards facts about the (our) past as options rather than fixtures. Such a being's perspective would deliver a reversal, for it, in the causal order; the crux of Price's perspectivalism is that there would be no more a fact of the matter about who is 'right' about the causal order - us or our imagined being - than there is a fact of the matter about whether it is us British or the French who are the foreigners.

Let's return briefly to the problems I raised earlier in connection with Ramsey's adherence to PIPSA. Price's account endorses PIPSA (at least for 'normal' cases where we have no grounds for suspending FPP), but explains our deep-rooted adherence to it in terms of the way our deliberative standpoint distinguishes between fixtures and options. But why is adherence to PIPSA rational? Its rationality stems from Price's point about the incompatibility between taking oneself to be able to decide whether $P$ and being able to know that $P$. We get to a short answer to the question about rationality if we borrow from Michael Dummett:

[T] here really is a form of incompatibility among these three beliefs ... (i) that an action $A$ is positively correlated with the subsequent occurrence of an event $B$; (ii) that the action $A$ is in my power to perform or not as I choose; and (iii) that I can know whether $B$ is going to take place or not independently of my intention to perform or not to perform the action $A$. The difference between past and future lies in this: that we think that, of any past event, it is in principle possible for me to know whether or not it took place 
independently of my present intentions; whereas, for many types of future event, we should admit that we are never going to be in a position to have such knowledge independently of our intentions. (Dummett 1964, 357)

Dummett's agenda, at least in part, is to show that it is not irrational to believe that one's action $(A)$ can affect the past (by bringing about some prior event $B$ ), so long as one gives up on (iii). But the claimed incompatibility of (i), (ii) and (iii) also gives us a handle on PIPSA. If I am deliberating about possible action $A$, then I will automatically regard $A$ as an action that 'is in my power to perform or not as I choose' (else there would be no point in deliberating about it). So, insofar as I hold FPP, for any past event or state of affairs $B$ I am rationally required to reject (i) - that is, I am rationally required to conceive $A$ as probabilistically independent of $B$, which is to say, to instantiate PIPSA.

Price summarises his somewhat longer answer to the same question about rationality $(1986,1991,1992)$ as: 'in the means-end context any [evidential] dependency would itself be a causal factor, so that the principle of total evidence would immediately undermine the judgement on which it was based' (2007, 281-2). Briefly, the idea is this. Imagine our decision-maker - Coco, say - deliberating on the basis of an evidential dependency of being in a prior pre-migrainous state $(B)$ on eating chocolate $(A)$ - that is, on the basis of $\operatorname{Pr}(B / A)>\operatorname{Pr}(B)$. (We are here assuming that Coco knows full well that $A$ is not a cause of $B$; correspondingly, he satisfies the third of Dummett's conditions. The issue is whether he should nonetheless be assuming an evidential dependency of $B$ on $A$, contrary to PIPSA.) Then, if he decides to desist from the chocolate, he will rightly count this very evidential relationship as a reason for, and hence a cause of, his decision. (Similarly, if he decides to eat the chocolate despite $\operatorname{Pr}(B / A)>\operatorname{Pr}(B)$ - we don't always behave rationally, after all again the evidential relationship will be a cause of his decision, since it played a role in his (faulty) deliberation.) But that - prior to Coco's decision - constitutes a new piece of evidence. So, given the principle of total evidence, Coco really ought to be asking himself not whether $A$ raises the probability of $B$ in general (this being the belief that is driving his conditional credence) but rather whether $A$ raises the probability of $B$ amongst people just like himself, viz, people whose decision about whether or not to eat the chocolate is caused by assigning credence $\operatorname{Pr}(B / A)>\operatorname{Pr}(B)$. And the answer to that question is 'no': people who decide on the basis of $\operatorname{Pr}(B / A)>$ 
$\operatorname{Pr}(B)$ will be people for whom being in a pre-migrainous state is not, in fact, correlated with chocolate-eating. (After all, Coco cannot tell just by reflecting on his deliberative process and its outcome whether or not he is in a pre-migrainous state: his decision procedure will go just the same either way. Similarly for everyone in just Coco's situation. So people in that situation and who decide to eat the chocolate are no more likely to be in a pre-migrainous state than are those who decide to desist.) So it turns out that Coco ought not to act on the basis of $\operatorname{Pr}(B / A)>\operatorname{Pr}(B)$ : doing so would be 'self-defeating'. Hence the rationality of taking past (i.e. knowable) states to be probabilistically independent of one's own prospective actions.

One might be inclined to insist at this point that in some circumstances one's future actions just $d o$ count as evidence of one's being in some past state. I hear the key in the door and wonder whether my partner has had a bad day at the office $(B)$. I quite legitimately conditionalise on whether this sound is closely followed by that of a wine bottle being opened $(A) . \operatorname{Pr}(B / A)$ is definitely greater than $\operatorname{Pr}(B)$-from my epistemic perspective and surely, therefore, from his too. So surely the underlying problem with PIPSA is that it is just false. Hence any fancy story, such as Price's, that is aimed at showing that is rational in such cases to ignore this evidential relation is bound to fail because it commits us to the absurd claim that it is sometimes rational to believe something that we know to be false.

This kind of response fails, however, to take account of the role that the deliberator's perspective is playing in the story. The difference between me and my partner is that it is not (unless I regard it as a matter for my potential intervention) up to me whether he opens the wine, whereas it is up to him. From his perspective assuming he is genuinely deliberating about whether to open the wine, as opposed to simply instinctively heading for the fridge - the probabilistic dependence of $B$ on $A$ is, to use Price's expression, 'inoperable' $(1986,199)$ : it is not something that he can rationally act on the basis of while simultaneously holding that (a) it is up to him whether to open the wine (Dummett's condition (ii)) and (b) his having had a bad day at the office is a 'fixture' (roughly, Dummett's condition (iii)). The claim is not that PIPSA is true, simpliciter; this would amount to the belief that our actions are never caused by prior states, and that belief is certainly false. Rather, it is that PIPSA applies to our own deliberative situation. As Ramsey says, '[i]t is possible to take one's future voluntary action as an intellectual problem ... But only by dissociating one's future self' $(1929,154 n$.) My partner can reasonably think to himself, 'I'll be 
able to tell just how bad my day has been by whether or not I open a bottle of wine'. But in thinking that way he is precisely not regarding whether or not he opens the wine as a matter of deliberation: he is 'dissociating' his future self. If he does regard it as a matter of deliberation, the evidential connection becomes inoperable.

It is through incorporating the idea of the deliberative perspective, then, that the Ramsey-Price view delivers the asymmetry of causation; and (to the extent that PIPSA is plausible) this is clearly preferable to the Hume-Blackburn position, which delivers asymmetry through the straightforward and correspondingly unsatisfying stipulation that causes precede their effects. ${ }^{5}$

There is, however, an obvious commonality between the two approaches in that they both, at bottom, find the root of causation in our epistemic situation. But they do so in slightly different ways, aside from the difference over the issue of the deliberative perspective. The Hume-Blackburn position takes causation to depend on our inferential commitments, while the Ramsey-Price position - or at least the Price version of it - takes causation to depend on evidential relations, understood as conditional credences. While these two phenomena are obviously related, they are not the same. In the next section I suggest a way of bringing these two wings of the projectivist approach to causation closer together by proposing, in effect, that we bring the notions of inference and evidence closer together. And I propose that we do this by drawing on a broadly Ramseyan approach to the connection between conditionals on the one hand - phenomena that have a history of being regarded as rules or 'inference tickets' - and the conditional credences that underpin the RamseyPrice account of causal asymmetry on the other. The problem about asymmetry for the Hume-Blackburn view remains, however, and I argue that the fact that other viable accounts of causation demand that we somehow 'sever' the link between a cause and its causes provides excellent evidence that the projectivist job cannot be done without embracing the Price-Ramsey view about the primary role of the agent's perspective.

\section{Conditionals and conditional credences}

According to Ramsey's account of unrestricted generalisations or what he calls 'variable hypotheticals' (such as 'all $\phi$ s are $\psi \mathrm{s}$ '), they 'are not judgments but rules for

\footnotetext{
${ }^{5}$ Blackburn himself makes no such stipulation, but he doesn't offer an alternative either.
} 
judging "If I meet a $\phi$, I shall regard it as a $\psi$ ". This cannot be negated but it can be disagreed with by one who does not adopt it' $(1929,149) .{ }^{6}$ Ramsey precedes this claim with the observation that ' $[\mathrm{m}]$ any sentences [including variable hypotheticals] express cognitive attitudes without being propositions; and the difference between saying yes or no to them is not the difference between saying yes or no to a proposition' (1929, 147-8). For Ramsey, then, variable hypotheticals are not propositions. They are not susceptible to truth and falsity, but they do express 'cognitive attitudes' and they are susceptible to agreement and disagreement; and they are rationally evaluable. ('Variable hypotheticals or causal laws form the system with which the speaker meets the future; they are not, therefore, subjective in the sense that if you and I enunciate different ones we are each saying something about ourselves which pass by one another like "I went to Grantchester", “I didn't” '(1929, 149).)

Ramsey's account of variable hypotheticals thus bears the obvious hallmarks of projectivism. Variable hypotheticals are not propositions and are therefore not representational; they rather express cognitive attitudes that are rationally evaluable. To make this vivid, consider just how close an affinity there is between the account just sketched and Hume's view of causation, interpreted along the projectivist lines sketched in $\S 2$ above. While Hume would appear to regard unrestricted universal generalisations as straightforward matters of fact rather than 'rules for judging', he does (I believe) hold that one could only have grounds for believing 'all $A$ s are (followed by) Bs' by way of judging that $A$ s cause Bs, since ' $[\mathrm{b}] \mathrm{y}$ means of that relation alone we can go beyond the evidence of our memory and senses' (1748/51, 26): causal generalisations 'form the system with which the speaker meets the future'. And the judgement that $A$ s cause $B$ s (while not a 'judgement' in Ramsey's restrictive

\footnotetext{
${ }^{6}$ Ramsey's reason (according to Fraser MacBride; see his 2005, especially 94-5) is roughly this: he rejects Frege's and Russell's view that the universal quantifier denotes a higher order property (so that 'everything is an $F$ ' means ' $F$ has the property of having universal application'). He also rejects Wittgenstein's proposal that universal generalisations are infinite conjunctions. So having failed to find a satisfactory way of characterising universal generalisations as judgements of one or other of these kinds, he rejects the view that they are judgements at all. (Thanks to Fraser MacBride here.) Interestingly in the context of this chapter - though somewhat tangentially - MacBride attributes Ramsey's dissatisfaction with the Frege-Russell view to his Humeanism.
} 
use of the term ${ }^{7}$ ) expresses a 'cognitive attitude', viz, one's reliance on the inference from $A$ s to $B \mathrm{~s}$ : a commitment, that is, to regarding future $A$ s that I meet as $B \mathrm{~s}$.

A similar - and similarly Humean - view of causal laws is to be found in Ryle's The Concept of Mind:

Law-statements are true or false ${ }^{8}$ but they do not state truths or falsehoods of the same type as those asserted by the statements of fact to which they apply or are supposed to apply. They have different jobs ... At least part of the point of trying to establish laws is to find out how to infer from particular matters of fact to other particular matters of fact, how to explain particular matters of fact by reference to other matters of fact, and how to bring about or prevent particular states of affairs. A law is used as, so to speak, an inference-ticket (a season ticket) which licenses its possessors to move from asserting factual statements to asserting other factual statements. (Ryle 1949, 122)

And here is a more explicit nod in Hume's direction:

... to speak of the 'rails of inference' suggests that inferring from diseases to bacteria is really not inferring at all, but describing a third entity [i.e. the rail that connects them]; not arguing 'because so and so, therefore such and such', but reporting 'there exists an unobserved bond between this observed so and so and that observed such and such'. But if we then ask 'What is this third, unobserved entity postulated for?' the only answer given is 'to warrant us in arguing from diseases to bacteria'. (1949, 122-3)

Ryle here suggests a move from the general (the variable hypotheticals that express laws) to the particular (the 'bond' between 'this observed so and so and that observed

\footnotetext{
${ }^{7}$ Note that Hume speaks about causal 'judgements' but not about causal beliefs (see my 2006, $\S 6.2$ ). I take this as evidence that he takes causal judgements to fail to latch onto 'matters of fact' (which are the objects of belief), and hence as evidence for the projectivist interpretation. So, roughly, what Ramsey means by 'judgement', Hume means by 'belief'.

${ }^{8}$ Ramsey of course disagrees with this claim, but it is not clear, given the view Ryle is about to express, that he (Ryle) is entitled to think that law-statements are true or false (unless he thinks that 'it is a law that $A \mathrm{~s}$ are followed by $B$ s' means something like 'the presence of an $A$ is grounds for inferring the subsequent presence of a $B^{\prime}$ ).
} 
such and such') that brings him closer to Hume than we have seen thus far from Ramsey. Hume's interest, after all, is in particular cases of causation - this billiard ball's causing that one to move - and (projectivistically conceived) is precisely claiming that the 'bond' between the two is constituted by our own inferential practices rather than a third element out there in the world that joins the two events together.

With this in mind, let's turn briefly from variable hypotheticals to indicative conditionals or 'ordinary hypotheticals'. Ramsey suggests that these, too, 'express cognitive attitudes without being propositions' (1929, 147-8). For example, if $A$ says 'If I eat this mince pie I shall have a stomach-ache' $(1929,147)$, someone, $B$, who disagreed with them would not be predicting that $A$ will eat the mince pie but will not have a stomach-ache, as they would if the indicative conditional were merely material implication. Instead, 'the ordinary hypothetical ... asserts something for the case when its protasis is true: we apply the Law of Excluded Middle not to the whole thing but to the consequence only' $(1929,148)$. In other words, in disagreeing with $A, B$ is doing something like imagining or supposing that $A$ eats the mince pie and asserting that in that imagined situation, $A$ will not get a stomach ache. This is of course very close to saying that ordinary hypotheticals express our inferential commitments: $A$ thinks that a stomach ache can reasonably be inferred from the supposition that he eats a mince pie (though that is not what he literally says when he utters the relevant conditional), and $B$, by contrast, thinks that the absence of a stomach ache can reasonably be inferred.

Ramsey later says:

Besides definite answers 'If $p, q$ will result', we often get ones 'If $p, q$ might result' or ' $q$ would probably result'. Here the degree of probability is clearly not a degree of belief in 'Not- $p$ or $q$ ', but a degree of belief in $q$ given $p$, which it is evidently possible to have without a definite degree of belief in $p, p$ not being an intellectual problem. $(1929,154)$

Thus, to use the above example, $A$ assigns a high credence to his getting a stomachache if he eats a mince pie, while $B$ assigns a low credence - hence their dispute. Correspondingly, $A$ has a high conditional credence in stomach-ache given mince pie, and $B$ has a low conditional credence. Ramsey's point is that since it is obvious that 
our view (if any) about the likelihood of $p$ ( $A$ 's eating a mince pie) is irrelevant to our conditional credence in $q$ (stomach-ache) given $p$, our degree of belief in 'if $p$, then $q$ ' is similarly insensitive to our degree of belief (if any) in $p$. So our degree of belief in the conditional cannot, even in part, be a function of our degree of belief in $p$; and in particular 'if $p$, then $q$ ' - the indicative conditional - cannot be the material conditional ' $p \supset q$ ' (since this is equivalent to ' $\sim p v q$ ').

What Ramsey points to here, then, is the idea that one's degree of belief in 'if $p$, then $q$ ' should match 'one's degree of belief in $q$ given $p$ '; that is, where probabilities are understood as rational credences, $\operatorname{Pr}(p \rightarrow q)=\operatorname{Pr}(q / p)$. Let's call this 'the Equivalence Thesis'. What we have, then, is, first, the thought that ' $p \rightarrow q$ ' expresses not a proposition but rather an inferential commitment of the kind just described, and, second, the thought that $\operatorname{Pr}(p \rightarrow q)=\operatorname{Pr}(q / p)$, again where probabilities are understood as rational credences. And, as it turns out (Lewis 1976), the second thought, if true, demands that ' $p \rightarrow q$ ' does indeed fail to express a proposition. As Dorothy Edgington puts it:

There is no proposition such that, necessarily, the probability of its truth is the conditional probability of something given something. Conditional probabilities cannot be made to behave as unconditional probabilities, the latter being probabilities of the truth of propositions. There are now many ways of proving this result: thinking that $B$ is probable on the supposition that $A$ is not equivalent to thinking that something-or-other is probable, simpliciter. $(2005,41)^{9}$

If ' $p \rightarrow q$ ' does indeed fail to express a proposition - if it fails to be truth-apt how should we understand it? ${ }^{10}$ Edgington's proposal, I take it - and I also take this to be roughly Ramsey's view - is that to assert ' $p \rightarrow q$ ' is, precisely, to assert that $q$ on the supposition that $p$ (where we should not, of course, take 'assertion' in this context to be the assertion of a proposition). So, in effect, $\operatorname{Pr}(p \rightarrow q)$ just is (and does not merely covary with) $\operatorname{Pr}(q / p)$ : each expresses my degree of belief in $q$ on the

\footnotetext{
${ }^{9}$ See Edgington 1995, $§ 6$ and 2005, $\$ 4$ for an explanation of this result.

${ }^{10}$ This is of course a big 'if'. Various authors have tried to avoid this result by, for example, claiming that it is the assertability of (rather than degree of belief in) ' $p \rightarrow q$ ' that covaries with $\operatorname{Pr}(q / p)$. See for example Jackson 1979.
} 
supposition that $p$. (After all, Edgington notes, " "on the supposition that $A$ " and "given $A$ " would appear to be mere stylistic variations on "if $A$ ", $(1995,262)$.)

What might all this have to do with causation? Well, we've already seen that Ramsey's account of variable hypotheticals has a close affinity with Hume's account of causation, projectivistically conceived. We can see his suggestion about indicative conditionals in the same light, but applying to single cases of causation ( $a$ caused, or will cause, $b$ ) rather than causal laws ( $A$ s cause $B \mathrm{~s}$ ). In other words (this is admittedly sketchy; the idea is fleshed out in a little more detail below), we might attempt to ground a projectivist account of causation in a projectivist account of conditionals, so that, roughly, to say that $a$ will cause $b$ is to express one's commitment to regarding $a$ 's occurrence as grounds for inferring $b$ 's occurrence, which in turn is to assert 'if $a$ occurs, then so will $b$ '. To stretch Ryle's metaphor, we might think of causal laws not as season tickets but as vouchers that entitle the holder to an unlimited number of single-trip inference tickets.

Leaving aside for now the issue concerning asymmetry and the agent's perspective, the proposal sketched above, together with the Equivalence Thesis, provides a way of bringing Price's view and the Hume-Blackburn view into closer alignment. The former takes causation to have its roots in evidential probabilities that is, credences of the form $\operatorname{Pr}(q / p)$. The latter, by contrast, takes causation to have its roots in our inferential commitments: our commitment to, for example, inferring the presence of a $Q$ when confronted with a $P$. The Equivalence Thesis gives us a straightforward way of conceiving the relationship between evidential probabilities and inferential commitments: the strength of my commitment to the inference from $p$ to $q$ - which on a Ramseyan understanding of conditionals amounts to $\operatorname{Pr}(p \rightarrow q)-$ just is my conditional credence in $q$ on the assumption that $p$ : $\operatorname{Pr}(q / p)$. So if we conceive causation as rooted in conditionals, understood in Ramseyan fashion, we thereby effectively collapse the distinction between Price's evidentialist approach and the Hume-Blackburn inferentialist approach (again, ignoring the asymmetry issue for now).

A little more flesh needs to be put on the bones, however. Most importantly, note that we can't infer anything at all about the causal relation between $p$ and $q$ just on the basis of $\operatorname{Pr}(q / p)$. My credence in its raining within the next five minutes conditional on the doorbell ringing is pretty high, and my credence in the Liberal 
Democrats winning the next election conditional on interest rates dropping by less than $1 \%$ in the next year is pretty low, but in each case the latter (the doorbell ringing; interest rates dropping) makes no difference to the likelihood of the former (rain; the Liberal Democrats winning): I assign a high degree of belief to rain given doorbell ringing simply because I assign a high degree of belief to rain, for example. So the value of $\operatorname{Pr}(q / p)$, just by itself, tells us nothing. What's needed, of course, is that $\operatorname{Pr}(q / p)$ is higher than $\operatorname{Pr}(q / \sim p)$. Causes make a (positive, I am assuming) difference to the likelihood of their effects. Price articulates the connection between conditional credences and causation by characterising causation in terms of the means-end relation, where causes are means and their effects are ends, and characterising the means-end relation, in turn, in terms of the recommendations of evidential decision theory (Menzies and Price 1989): I will (rationally) do $p$ as a means to getting $q$ just when $\operatorname{Pr}(q / p)>\operatorname{Pr}(q / \sim p)$.

Suppose we follow Price's advice here. What remains of the thought that causation is a matter of the expression of our inferential commitments? Again, appeal to the Equivalence Thesis gives us an answer. The Equivalence Thesis entails that $\operatorname{Pr}(q / p)>\operatorname{Pr}(q / \sim p)$ iff $\operatorname{Pr}(p \rightarrow q)>\operatorname{Pr}(\sim p \rightarrow q)$, and we can think of the latter inequality as enshrining a difference between the strength of the commitment to inferring $q$ from $p$ and the strength of the commitment to inferring $q$ from $\sim p$. ('Strength of commitment' here means something like the extent to which I regard $p$ as legitimate grounds for inferring q.) If (and of course this is a big 'if') we accept all this, then, it turns out that causation is not a straightforward expression of an inferential commitment; rather, it is an expression of a relative inferential commitment: a greater commitment to inferring $q$ from $p$ than to inferring $q$ from $\sim p$.

The above is only a rough first pass, however; clearly it would be incorrect to hold that $c$ is a cause of $e$ iff $\operatorname{Pr}(p \rightarrow q)>\operatorname{Pr}(\sim p \rightarrow q)$ (or, correspondingly, iff $\operatorname{Pr}(e / c)$ $>\operatorname{Pr}(e / \sim c))$. If the relationship of causation to probability were that simple, the vast majority of the literature on causation over the last 50 years or so would never have needed to be written. The point is rather to locate what the most basic kind of causal relationship amounts to, on a projectivist understanding of causation according to which our epistemic practices underlie the (projected) causal structure of the world. It's the analogue, in other words, of a non-projectivist who wants to reduce causation to objective probability relations saying that causes raise the probability of their 
effects: a slogan that is strictly speaking false, but which captures the heart of the theory. If we want a workable theory, of course, the evidential relationships on which we build causal relations will have to be a lot more sophisticated.

Here, however, the projectivist has some grounds for optimism. After all, there is a huge wealth of literature, particularly in the 'causal modelling' tradition, whose purpose is to shed light on the norms that govern the inference from probabilistic to causal relationships, and which, in some cases, explicitly aims to shed light on the nature of causation itself (e.g. Woodward 2003; such views tend to go by the name of 'interventionist' or 'manipulability' theories of causation). Such accounts are generally explicitly concerned with objective probabilities rather than credences, but since the two are obviously connected (indeed we might, in the spirit of Lewis 1986a, hold that it is credences that underpin 'objective' probabilities and not the other way around), the projectivist can, in effect, help herself to the results while interpreting them in a distinctively projectivist spirit.

Mention of the causal modelling literature brings us conveniently back to the question about the asymmetry of causation. In $\S 2$ we saw that the Ramsey-Price view provides an account of causal asymmetry in terms of the distinctive perspective of the deliberating agent, for whom past states are probabilistically independent of contemplated actions (PIPSA). PIPSA can be seen as a projectivist analysis of the requirement common to all interventionist or manipulability theories of causation that the probabilistic relations that underpin causation result from 'interventions'. An intervention on a system is defined in causal terms: to intervene is, roughly, to fix the value of a variable $X$ in such a way as to break any causal connection between $X$ and its causal ancestors. Thus, for example, if $A$ is a cause of $B$ then ordinarily $\operatorname{Pr}(A / B)>$ $\operatorname{Pr}(A)$. But if $B$ is an intervention, this - by stipulation - breaks the relationship between $B$ and $A$, so that $\operatorname{Pr}(A / B)=\operatorname{Pr}(A)$ : the causal and probabilistic relationships between $B$, considered as an intervention, and $A$ line up. (Intuitively: normally, the barometer pointer's pointing at rain $(B)$ raises the probability of low atmospheric pressure $(A)$. But if you simply move the barometer pointer with your finger so that it points at rain, then you break the causal connection between $A$ and $B$, and so you don't increase the probability that the atmospheric pressure is low.) The definition of an intervention is explicitly circular; PIPSA turns the same trick without the circularity. 
I said earlier that the major problem with the Hume-Blackburn position is that it fails to provide a satisfying account of causal asymmetry - something that the Ramsey-Price view manages to do. From a broadly projectivist point of view, the fact that interventionist theories need to rely on a notion of an intervention that is defined in explicitly causal terms serves to make the same point. Probabilistic relations fail to distinguish effects from causes (and hence fail to distinguish the case where $A$ is a cause of $B$ from the case where $B$ is a cause of $A$ ) unless we can help ourselves to a special class of cases where the 'normal' probabilistic dependencies break down. That interventionists apparently cannot do this in a non-circular way strongly suggests that someone who seeks to account for causation in terms of features of our evidential situation will not be able to turn the trick - they will not be able to find a special class of cases where the 'normal' conditional credences are inappropriate - unless they do so in just the way that Ramsey and Price suggest, that is, by appealing to the deliberative perspective.

\section{Projectivism vs. Lewisian objectivism}

Characterising causation in broadly conditional terms is of course a familiar idea already, thanks to the counterfactual analysis of causation. I end by conducting a compare-and-contrast exercise between the kind of projectivist view sketched above on the one hand and Lewis's objectivist account of causation on the other. The moral will be that while in one sense the projectivist and the Lewisian objectivist are both fellow Humean travellers (or at least have views that can be used to serve the Humean cause), a deeper difference between the projectivist and Lewisian objectivist conceptions of what a metaphysical account of causation is for makes a direct costbenefit analysis of their relative virtues and vices rather difficult to conduct. On the other hand, a recent attempt by Barry Loewer (2007) to provide a better account of causal asymmetry than is offered by Lewis appears to move the two views a little closer together.

Ramsey holds that ' $[\mathrm{t}]$ he world, or rather that part of it with which we are acquainted, exhibits as we must all agree a good deal of regularity of succession ... over and above that it exhibits no feature called causal necessity' (Ramsey 1929, 160). And this decidedly Humean view is one that Lewis signs up to as well, in the sense that causal relations supervene on (and so in some sense are nothing 'over and above') the Humean mosaic - the 'vast mosaic of local matters of particular fact, just 
one little thing and then another' (1986b, ix), or, loosely speaking, the pattern of 'regularity of succession'. The nub of the difference between Ramsey and Lewis is that Ramsey (along with Hume, Blackburn and Price) holds that causation is something that we bring to the table as a result of our own distinctive epistemic situation. For Lewis, by contrast, while causation is not a fundamental feature of reality - it is no part of the Humean supervenience base - causal facts are as objective as can be: as objective as facts about rocks, planets or tigers.

One place where this difference plays itself out - and which, I think, provides at least a modicum of intuitive support for a projectivist rather than objectivist position - is the notion of dependence. It is the notion of dependence that underpins conditional accounts of causation, since (at least if we ignore the material conditional) the guiding idea is that the dependence of effects on causes is akin to the dependence of the consequents of conditionals on their antecedents. When Lewis (1973a) introduces the counterfactual analysis, he notes that the notion of causal dependence cuts, as it were, two ways:

e depends causally on $c$ iff the family $O(e), \sim O(e)$ depends counterfactually on the family $O(c), \sim O(c)$. As we say it: whether $e$ occurs or not depends on whether $c$ occurs or not. The dependence consists in the truth of two counterfactuals: [(i)] $O(c) \square \rightarrow O(e)$ and [(ii)] $O(c) \square \rightarrow \sim O(e) .(1973 \mathrm{a}, 563)$

As he goes on to point out, however, given his account of counterfactuals (i) is trivially satisfied if $c$ and $e$ actually occur, while (ii) is trivially satisfied if neither of them do. This is because the truth condition of any counterfactual with a true antecedent is simply that of the indicative conditional, which Lewis takes to be the material conditional (so if $A$ is true, $A \square \rightarrow B$ is true iff $A \supset B$ is true - that is, iff $B$ is true). Since the tradition of the counterfactual analysis has been more or less exclusively concerned with causation between actual events, (i) has tended to be ignored in later discussions. Correspondingly, causation between particular events in this tradition is usually discussed in the past tense: we take the occurrence of $c$ and $e$ for granted and hence as having already happened, and ask whether the latter counterfactually depended on the former. 
The Ramseyan approach - and indeed the projectivist approach more generally - comes at causation from the other side: the point of our causal talk, on this view, is to express our inferential commitments, and those commitments are largely (though not exclusively) of interest because of their role in prediction and control. I am more interested whether or not I will have a stomach-ache $(e)$ as a result of eating the mince pie sitting temptingly on the plate $(c)$ than I am, having already scoffed the mince pie and suffered a stomach-ache, in whether or not the former caused the latter. Arguably, it is only in such cases - cases where we are uncertain about what will happen - that we really capture the two-way dependence (whether-or-not on whetheror-not) that Lewis claims to enshrine in his account of causal dependence. If we consider only cases where we are already certain of $c$ and $e-$ most obviously because they lie in the past - one of the two counterfactuals which supposedly collectively capture two-way dependence, namely $O(c) \square \rightarrow O(e)$, is trivially true; hence its truth fails to capture any notion of dependence at all.

My somewhat speculative suggestion is that the failure of Lewis's account to capture the two-way dependence he seems to be aiming at in his definition of causal dependence is, at bottom, due to his objectivism about causation. We Humeans can make sense of two-way dependence if we take as the starting-point of our account of causation future-directed rather than past-directed conditionals: 'what will happen if this happens - and what will happen if it doesn't?', rather than 'what would have happened if this hadn't happened?' (where the second question - 'what would have happened if this actually-occurring event had happened?' - gets a trivial answer). And to take future-directed conditionals as the appropriate starting-point takes us a good distance towards accepting that it is our epistemic position, with our distinctive temporal orientation, that underlies our attribution of causal structure to the world.

From the point of view of the whole of the four-dimensional Humean mosaic, past and future, my own temporal location and orientation are irrelevant: the various subjunctive conditionals that underpin the causal facts on a Lewisian story just are what they are whether, from my point of view, they happen to be future-or pastdirected. Thus any two randomly-picked events $c$ and $e$ in (or supervening on) the Humean mosaic will trivially satisfy $O(c) \square \rightarrow O(e)$; it is only $O(c) \square \rightarrow \sim O(e)$ that uncovers dependence relations, and so causal dependence is in effect merely one-way dependence, Lewis's definition notwithstanding. But from my point of view, all but a 
tiny corner of the vast Humean mosaic is hidden from me; and it is for that reason that conditionals concerning the as-yet-unexcavated part of the mosaic are of very great interest (and again, it is therefore two-way dependence we're interested in here: what will happen if this happens, and what will happen if it doesn't?), while those concerning only the fixtures - what I already know about - are of very little interest. ${ }^{11}$ We can thus enshrine two-way dependence in our account of causation, but only by taking the asymmetry in our epistemic concerns as the starting-point of our theory of causation - thereby abandoning objectivism. ${ }^{12}$

Projectivism about causation is, of course, not everyone's cup of tea. From a Humean point of view the choice between projectivism and broadly Lewisian objectivism is far from straightforward, and one reason for this is that they are not merely competing metaphysical theories; they enshrine different conceptions of what our metaphysical theorising about causation is for. Hume himself starts out from the assumption that ' $[\mathrm{b}] \mathrm{y}$ means of [the causal relation] alone we can go beyond the evidence of our memory and senses' $(1748 / 51,26)$ - an assumption, that is, about the role that causation plays in our cognitive lives, and in particular in our inferential practices. And, on finding that no feature of reality could possibly play that role (since it would have to be both observable and inference-licensing; and not only is there no such feature, but we don't have the slightest idea what such a feature could possibly be like), he locates the source of the concept in our inferential practices themselves, rather than in the world. Hume's projectivism is thus driven by his conception of the

\footnotetext{
${ }^{11}$ They are of some interest, of course; in particular we can legitimately regard past-directed counterfactuals ('if I hadn't eaten that mince pie, I wouldn't have got a stomach ache') as grounds for believing future-directed conditionals ('if I eat a mince pie now, I'll get a stomach-ache'). On the other hand, past-directed subjunctives of the form $O(c) \square \rightarrow O(e)$, for actual $c$ and $e$, are no use to anyone.

12 One might object that to the line of thought pursued above that the entailment of $A \square \rightarrow B$ by $A \& B$ ) is a feature of Lewis's analysis that can and should be rejected, consistent with the view that causation is an objective relation to be analysed in counterfactual terms, on the grounds that there are plenty of cases where, intuitively, $A \& B$ is true and $A \square \rightarrow B$ false; see for example Bennett 1974, Fine 1975, Penzek 1997 and McGlynn 2012. This objection deserves more space than I can give it here; my own view, however, is that the cases where the inference is alleged to fail are far from compelling. Mistakenly believing that Casper didn't go to the party, and unaware that he is normally the kiss of death to any social gathering (indeed, this particular party was good despite his presence), I say: 'If Casper had gone, it would have been a good party'. What I say is undoubtedly unwarranted, but - if conditionals are truth-apt - nonetheless true, I think (pace Bennett 1974, 387-8 and McGlynn 2012, 277).
} 
point of the concept of causation; and I take it that this basic outlook is shared by Ramsey, Blackburn and Price.

The Lewisian worldview has a very different hue: a broadly Humean metaphysics is the starting-point (no necessary connections in the supervenience base, please), and our aim as metaphysicians is to construct theories of the supervening facts that retain as much as possible of our common-sense theory, consistent with that metaphysics - common-sense theory being the major source of data when it comes to theory-construction (it is 'far beyond our power to weave a brand new fabric of adequate theory ex nihilo, so we must perforce conserve the one we've got' (Lewis 1986c, 134)). Since the purpose and genealogy of our concept of causation form no part of that common-sense theory - which is, after all, a theory of causation and not a theory of the aetiology of the concept of causation - it is simply no part of Lewis's project to consider how and why we might have come to think of the world in causal terms.

Despite the common commitment to Humeanism, then, the projectivist and the Lewisian objectivist are locked into something of a stalemate. In particular, the projectivist's reason for denying that causal claims are genuinely truth-apt, which stems, in effect, from the perceived need to root the concept of causation in our epistemic situation and corresponding inferential practices, cuts no ice with the Lewisian objectivist, since the latter is not primarily interested in what the concept of causation is for. Correspondingly, should the objectivist complain to the projectivist that truth-aptness is non-negotiable aspect of our common-sense theory ('don't we think of causal facts as genuine facts? Don't we take our causal claims to be true and false?'), the likely response will be a reminder that projectivism is not the same as anything-goes subjectivism. Our causal talk is norm-governed: causal claims can correspondingly be warranted or unwarranted, subject to correction in the face of additional evidence, and so on. And that, the projectivist is likely to insist, is all that our common-sense theory really commits us to.

One issue in particular, however, provides a potential common basis for evaluating the relative merits of the projectivist and the Lewisian objectivist accounts, and that is the issue of the asymmetry of causation. I argued earlier that, since Hume's stipulation that causes precede their effects is deeply unsatisfying, we should prefer the Ramsey-Price version of projectivism to the Hume-Blackburn version, since the agent's perspective - via PIPSA - provides the basis for the needed asymmetry. 
Counterfactual accounts also depend upon an adequate story about the asymmetry of causation; and Lewis's story runs in terms of what he calls the 'asymmetry of overdetermination', which in turn grounds the asymmetry of counterfactual dependence: by and large, counterfactual dependence runs from the past to the future (Lewis 1979). But this account has come in for criticism (e.g. Elga 2001). Two recent and closely related attempts to better account for asymmetry within a broadly Lewisian framework have come from David Albert (2001) and Barry Loewer (2007). Both derive the asymmetry of counterfactual dependence from thermodynamic asymmetry, by building what they call the 'past hypothesis' $(\mathrm{PH})$ - which postulates a very low energy state at or near the beginning of the universe - and PROB, 'a uniform probability distribution over the physically possible initial conditions compatible with PH; that is, the initial macro state of the universe' (Loewer 2007, 300), into the laws of nature (again conceived in broadly Lewisian, i.e. best-system, terms). ${ }^{13}$ What this gets us is an objective, asymmetric probabilistic structure, and therefore a temporal direction.

Leaving aside all the detail, what is interesting, in the current context, about Loewer's proposal in particular is its close affinity to the Ramsey-Price account of causal asymmetry. PH and PROB get us temporal asymmetry; what we now need is a similarly asymmetric account of counterfactuals, if we are to be in a position to offer a counterfactual analysis of causation that does not rest on an implausible account of causal asymmetry. Loewer's proposal in this regard depends upon a special class of future subjunctive 'decision conditionals' of the form:

(\$) If at $t$ I were to decide $D$, then the probability of $B$ would be $x^{\prime}(2007,317)$,

where ' $(\$)$ is true if $\operatorname{Pr}(B / M(t) \& D(t))=x$ ' (ibid.) - where $M(t)$ is the macro state of the world at $t$ and the probability is just that derived from PROB, $\mathrm{PH}$, and the (symmetric and deterministic) dynamical laws. We conditionalise on the macro state because it is 'the natural limit on the extent of accessible information' - which is just another way of saying that the macro state of the world just prior to my decision is amongst the 'fixtures'. Thus Loewer's account explicitly builds (a somewhat idealised

\footnotetext{
${ }^{13}$ The 'past hypothesis' is not really a hypothesis about past - this would make the account of temporal direction blatantly circular - but about a boundary condition: $\mathrm{PH}$ will have to, as Loewer puts it, 'earn the title "the past hypothesis" ' $(2007,304)$.
} 
version of) our own temporally oriented epistemic situation into the starting-point for his account of the kind of conditional that might serve to ground a theory of causation. Moreover, and relatedly, that starting-point (as enshrined in (\$)) is just the kind of future-directed conditional that, I argued above, is what we need if we want to capture a genuinely 'two-way' notion of causal dependence. Finally, Mathias Frisch argues that Albert's and Loewer's claim that PH and PROB count amongst the laws pushes them in a broadly pragmatist direction: Albert and Loewer, he thinks, need to accept that ' $[\mathrm{t}]$ he yardstick for simplicity and informativeness [i.e. the criteria that govern what the best system is, and hence what the laws are] is how practically useful a system is for beings like us - how well it allows us to make our way about in the world' (2011, 1006).

Of course, none of this amounts to embracing projectivism about causation. But if Albert's and Loewer's views are along the right lines - if that kind of account of causal asymmetry really is the kind of account that a Lewisian should embrace then the gap between projectivism (of the Ramsey-Price variety) and Lewisian objectivism is starting to look rather smaller than it appeared. Or, to put it another way, perhaps a broadly Lewisian programme will in the end have to embrace the agent's epistemic situation as the key to understanding causation after all.

\section{Conclusion}

The overall purpose of this chapter has been to consider the prospects for a projectivist account of causation - an account that, like Lewis's counterfactual analysis, could be used to serve a broadly Humean agenda. A version of projectivism that grounds the asymmetry of causation in the agent's epistemic situation fares better, I have argued, than one that does not; here I side with Ramsey and Price rather than Hume and Blackburn. I have also tried to show how one can align a broadly Pricean projectivism - which grounds causation in the conditional probabilities assigned by the rational decision-maker - more closely with its Ramseyan roots by making an explicit connection, as Ramsey does, between conditional probabilities and the probabilities of conditionals. This has the advantage of providing some independent motivation for the claim that causal claims are not truth-apt, since this is a consequence of the plausible thesis that $\operatorname{Pr}(p \rightarrow q)=\operatorname{Pr}(q / p)$. I have also argued that there is at least prima facie reason to think that conditionals whose credences express 
the agent's epistemic situation better capture 'two-way' dependence than do Lewisian counterfactuals, and, finally, that Lewisians may after all have to move closer to the projectivist position than they may have liked, if they are to make sense of causal asymmetry.

\section{Bibliography}

Albert, D. 2001. Time and Chance. Cambridge, MA: Harvard University Press.

Beebee, H. 2006. Hume on Causation. Abingdon: Routledge.

Bennett, J. 1974. 'Counterfactuals and Possible Worlds', Canadian Journal of

Philosophy, 4: 381-402.

Blackburn, S. 1984. Spreading the Word. Oxford: Oxford University Press.

-- 1987. 'Morals and Modals', in C. Wright \& G. Macdonald (eds), Fact, Science and

Value, Essays in Honour of A. J. Ayer's Language, Truth and Logic, Oxford:

Blackwell, 1987. Reprinted in his 1993, 52-74.

-- 1990. 'Hume and Thick Connexions', Philosophy and Phenomenological Research, 50 (Supp.): 237-50.

-- 1993. Essays in Quasi-Realism. New York: Oxford University Press.

-- 2008. How to Read Hume. London: Granta Publications.

Coventry, A. 2006. Hume's Theory of Causation. New York: Continuum Press.

Dummett, M. 1964. 'Bringing About the Past', The Philosophical Review, 73: 338-59.

Edgington, D. 1995. 'On Conditionals', Mind, 104: 235-329.

-- 2005. 'Ramsey's Legacies on Conditionals and Truth', in H. Lillehammer and D.

H. Mellor (eds), Ramsey's Legacy, Oxford: Oxford University Press, 37-52.

Elga, A. 2001. 'Statistical Mechanics and the Asymmetry of Counterfactual

Dependence', Philosophy of Science, 68 (Proceedings): S313-24.

Fine. K. 1975. 'Critical Notice: D. Lewis, Counterfactuals', Mind, 84: 451-8.

Frisch, M. 2011. 'From Arbuthnot to Boltzmann: The Past Hypothesis, the Best

System, and the Special Sciences', Philosophy of Science, 78: 1001-1011.

Ginet, C. 1962. 'Can the Will be Caused?', Philosophical Review, 71: 49-55.

Hume, D. 1739-40. A Treatise of Human Nature, ed. L. A. Selby-Bigge, 2nd edition, revised and ed. P.H. Nidditch, Oxford: Clarendon Press (1978).

-- 1748/1751. Enquiries Concerning Human Understanding and Concerning the

Principles of Morals, ed. L.A. Selby-Bigge, 3rd edition, revised and ed. P.H.

Nidditch, Oxford: Clarendon Press (1975). 
Jackson, F. 1979. 'On Assertion and Indicative Conditionals', The Philosophical Review, 88: 565-89.

Lewis, D. K. 1973a. 'Causation', The Journal of Philosophy, 70: 556-67.

-- 1973b. Counterfactuals. Oxford: Blackwell.

-- 1976. 'Probabilities of Conditionals and Conditional Probabilities', The

Philosophical Review, 85: 297-315.

-- 1979. 'Counterfactual Dependence and Time's Arrow', Nous, 13: 455-76.

-- 'A Subjectivist's Guide to Objective Chance', in his Philosophical Papers, Vol. II

(New York: Oxford University Press), 263-93.

-- 1986b. 'Introduction', Philosophical Papers, Vol. II. New York: Oxford University Press.

-- 1986c. On the Plurality of Worlds. Malden, MA: Blackwell.

Loewer, B. 2007. 'Counterfactuals and the Second Law', in Price \& Corry 2007, 293 326.

MacBride, F. 2005. 'Ramsey on Universals', in H. Lillehammer and D. H. Mellor (eds), Ramsey's Legacy, Oxford: Oxford University Press, 83-104.

McGlynn, A. 2012. 'The Problem of True-True Counterfactuals', Analysis, 72: 27685.

Menzies, P. \& H. Price. 1993. 'Causation as a Secondary Quality'. The British Journal for the Philosophy of Science, 44: 187-203.

Penzek, A. 1997. 'Counterfactuals with True Components', Erkenntnis, 46: 79-85.

Price, H. 1986. ‘Against Causal Decision Theory’, Synthese, 67: 195-212.

-- 1991. 'Agency and Probabilistic Causality', British Journal for the Philosophy of Science, 42: 157-76.

-- 1992. 'The Direction of Causation: Ramsey's Ultimate Contingency', PSA: The

Proceedings of the Philosophy of Science Association, 1992: 253-67.

-- 1998. 'Two Paths to Pragmatism, II', in R. Casati and C. Tappolet (eds), European

Review of Philosophy, 3: 109-47.

-- 2007. 'Causal Perspectivalism', in Price \& Corry 2007, 250-92.

-- \& R. Corry (eds). 2007. Causation, Physics, and the Constitution of Reality:

Russell's Republic Revisited. Oxford: Oxford University Press.

Ramsey, F. P. 1929. 'General Propositions and Causality', in his Philosophical

Papers, ed. D. H. Mellor, Cambridge: Cambridge University Press, 145-63.

Ryle, G. 1949. The Concept of Mind. London: Hutchinson's University Library. 
Sorensen, R. 1984. 'Uncaused Decisions and Pre-decisional Blindspots', Philosophical Studies, 45: 51-6.

Woodward, J. 2003. Making Things Happen: A Theory of Causal Explanation. Oxford: Oxford University Press.

Wright, J. P. 1983. The Sceptical Realism of David Hume, Manchester: Manchester University Press. 